\title{
Sick Leave and Costs in Active Workers With Chronic Osteoarthritis Pain in Spain: Outcomes of the OPIOIDS Real World Study
}

Antoni Sicras-Mainar ( $\nabla$ ansicras@atryshealth.com )

Atrys https://orcid.org/0000-0002-8232-293X

Juan Carlos Tornero

Hospital Clinico Universitario de valencia

F Vargas

Centro salud tenerife

I Lizarraga

Pfizer Inc

A Sicras

Atrys

J Rejas

Pfizer

\section{Research}

Keywords: osteoarthritis, opioids, sick leave, cost, active workers

Posted Date: December 1st, 2020

DOI: https://doi.org/10.21203/rs.3.rs-115760/v1

License: (c) (1) This work is licensed under a Creative Commons Attribution 4.0 International License.

Read Full License

Version of Record: A version of this preprint was published at Open Access Rheumatology: Research and Reviews on March 1st, 2022. See the published version at https://doi.org/10.2147/OARRR.S346746. 


\section{Abstract}

Objective

To evaluate sick leave and its costs in active workers who initiate opioid treatment for moderate/severe chronic osteoarthritis $(\mathrm{OA})$ pain.

Methods

Secondary analysis of the longitudinal, retrospective OPIOIDS study using electronic medical records $(E M R)$ of patients aged $\geq 18$ years who started opioid treatment for chronic OA pain between 2010 and 2015 after treatment failure with usual analgesics. The follow-up period was 36 months from the index date, and the days of sick leave and their cost were analyzed.

Results

A total of 5,089 EMRs of OA chronic pain patients aged 56.8 years (SD: 4.6$), 56.6 \%$ male, were analyzed: $73.3 \%$ of patients started treatment with a weak opioid and $26.7 \%$ a strong opioid. At 36 months, adherence was $21 \%$ (strong opioids $15.4 \%$, weak opioids: $23 \%$; $p<0.001$ ), and $77 \%$ of patients had at least one sick leave related with OA chronic pain, with a mean total days off work of 93 days in all actively working patients (120.5 days in patients with sick leaves). In $16.9 \%$ it lasted $\geq 6$ months. Pain reduction was modest $(-1.2$ points; $-4.0 \%, p<0.001)$. The cost of sick leave was $€ 2,594$ patient/year and was associated $(p<0.05)$ with age $(\beta-0.043)$, female sex $(\beta-0.035)$, comorbidity $(\beta-0.034)$ and strong opioid use $(\beta-0.037)$.

Conclusions

Active workers who started opioid treatment for chronic osteoarthritis pain showed an increased frequency of sick leave and cost to society, with modest pain reduction. Age, female sex, comorbidity, and strong opioids were factors associated with the cost of sick leave.

\section{Introduction}

Osteoarthritis $(\mathrm{OA})$ is a degenerative joint pathology characterized by cartilage deterioration, with a proliferative reaction of the subchondral bone and inflammation of the synovial membrane [1]. It is estimated that $6-24 \%$ of adults have chronic OA pain and the incidence increases with age [2,3]. In Spain, according to the EPISER study [4], the prevalence of OA in persons aged $>40$ years is $29.4 \%$. Therapeutic approaches include non-pharmacological measures, drug treatment and joint replacement surgery in the most disabling cases [5]. Drug treatments include nonsteroidal anti-inflammatory drugs (NSAIDs), which are often used in patients who do not respond to first-choice analgesics such as acetaminophen [6]. Tramadol is the weak opioid with the greatest evidence of efficacy and safety, while strong opioids are used for moderate to severe pain with an insufficient response to other treatments [7,8]. The utility of strong opioids is proven in cancer pain relief, but their use in chronic non-cancer pain relief is unclear 
$[5,7,8]$. Some scientific societies, such as the OARSI or the American College of Rheumatology (ACR) discourage their use in $O A$ treatment $[1,9]$.

The chronic pain and disability associated with OA have a negative effect on the quality of life, and are one of the main causes of days off work due to sick leave which, together with lower occupational productivity, result in high social costs [1,8,10-15]. Studies have estimated that one in four active workers with OA leave the workplace before the normal retirement age [16]. The mechanisms explaining the involvement of $O A$ in occupational performance are not entirely clear [15]. Most studies have found that pain and/or functional joint deterioration are the main reasons for lost work productivity [10]. Joint pain may have a direct impact on occupational productivity, regardless of comorbidity or other associated factors. However, it may also have an indirect impact, in which joint pain causes physical limitations, depression, poor adaptation and poor sleep quality, which in turn lead to lost productivity [17]. In addition, opioid use in patients with OA has increased and its relationship to the incidence of days off work due to sick leave and its cost is not clear $[18,19]$. The OPIOIDS study, carried out under conditions of usual medical practice in Spain [20], collected information on the impact of opioids in the treatment of chronic OA pain refractory to regular analgesics on different outcomes including lost productivity due to sick leave and its costs. The objective of this study was to carry out a secondary analysis of the OPIOIDS study to assess lost occupational productivity (days of temporary sick leave) and the associated cost in active workers initiating opioid treatment for chronic pain due to OA lasting more than three months in usual clinical practice.

\section{Patients And Methods}

\section{Design and study population}

We conducted a secondary analysis of the longitudinal, multicenter, retrospective OPIOIDS (Outcomes in

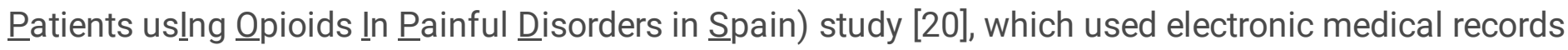
(EMR) from the BIG-PAC registered health database (The European Network of Centers for Pharmacoepidemiology and Pharmacovigilance; http://www.encepp.eu/encepp-/viewResource.htm? id29236) of records of an allocated population of 1.8 million from seven Spanish autonomous communities [21]. EMRs were anonymized according to Organic Law 3/2018, of December 5, on the Protection of Personal Data and guarantee of digital rights

(https://www.boe.es/eli/es/lo/2018/12/05/3). The OPIOIDS study was classified by the Spanish Agency for Medicines and Health Products and approved by the Ethics Committee of the Hospital of Terrassa (Barcelona). The Strengthening the Reporting of Observational Studies in Epidemiology (STROBE) statement guidelines for reporting observational studies were followed [22].

We included the EMR of patients who started a new treatment with strong or weak opioids, alone or combined with other analgesics, for the treatment of moderate to severe ( $\geq 5$ points on the numerical pain scale) chronic nociceptive pain ( $\geq 3$ months) in any site due to OA between 1/01/2010 and $31 / 12 / 2015$ [23]. Patients were followed for a maximum of 3 years. Patients had to be previously treated 
with $\geq 1$ first-line analgesic such as acetaminophen, metamizole and/or nonsteroidal anti-inflammatory drugs (NSAIDs). EMRs were obtained during the 12 months before the index date and over the next 36 months. The index date was the initiation of a new opioid treatment, starting from the date of diagnosis of chronic nociceptive pain due to OA. Additional inclusion criteria were (a) age $\geq 18$ years, (b) occupationally active, $c$ ) patients active in the database ( $\geq 2$ health records in the computer system) a minimum of 12 months before the start of the study, (d) ensured regular monitoring ( $\geq 2$ health records in the computer system from the index date), and (c) inclusion in chronic prescription program (with a record of the daily dose, time interval and duration of each treatment administered ( $\geq 2$ prescriptions during the follow-up period)). Exclusion criteria were (a) displaced or out-of-area subjects; (b) permanently institutionalized patients, c) terminal illness and/or dialysis (ICD-10:N18), d) neuropathic pain/radiculopathy (ICD-10: G50-65) or cancer (ICD-10: G89.6), and e) not occupationally active (retired, unemployed, permanent work disability, early retirement and/or maternity leave).

\section{Definition of diagnosis and study cohorts}

Diagnoses were obtained from the International Classification of Diseases (10th edition) Clinical Modification (ICD-10-CM) (https://eciemaps. mscbs.gob.es). Chronic pain was defined as pain that persisted for $\geq 3$ months. The site of pain was a) hip and knee (M16, M17), b) lumbar (M54.5), and other sites (M15, M18, M19, M40, M41) according to medical criteria. Two study cohorts were developed according to type of opioid (weak or strong) according to the Anatomical Therapeutic Chemical Classification System (ATC)[24]. The index date was the start of a new opioid treatment (weak or strong) from the date of diagnosis of chronic nociceptive pain due to OA. Adherence, persistence, medication possession ratio (MPR) and discontinuation definitions were as previously described in the OPIOIDS study [20].

\section{Demographic variables, comorbidity and medication administered}

Demographic and comorbidity variables were age (continuous and by range: $18-44,45-54$ and $\geq 55$ years on the index date), sex and body mass index $\left(\mathrm{BMl}, \mathrm{Kg} / \mathrm{m}^{2}\right)$ and the personal medical history. The Charlson comorbidity index and the number of chronic comorbidities were used as a summary variable of general comorbidity and an approximation of patient severity [25]. The medications (active ingredients) indicated for chronic OA pain were obtained (ATC N02AA01 to N02AX06) from pharmacological prescription records. The choice of medication in a specific patient was at the physician's discretion. The type and medical specialty that initiated the prescription was determined (Supplementary table S1).

Cost of days of sick leave

The cost of days of temporary work disability from the social perspective was determined by the human capital method (mean salary of the replacement of the active patient [ $€ 119.44$ per day not worked]), source: Spanish Institute of Statistics (INE))[26]. Days of sick leave were expressed as absolute and relative values (in patients with sick leave), and as the mean days of sick leave per patient (patients with/without sick leave [0 days of sick leave]). 
Clinical effectiveness was obtained using the variation in pain intensity on an 11-point numerical pain scale (5-7; moderate pain, $>7$; severe pain) from the closest date before the start date (index date) and the end date of the study [23]. The absolute variation in the natural and relative units was calculated in percentage changes from the baseline value.

\section{Statistical analysis}

A descriptive, univariate statistical analysis was made. Qualitative data were described using absolute and relative frequencies. The $95 \%$ confidence intervals $(\mathrm{Cl})$ for parameter estimation were based on the total number of subjects with no missing values. ANOVA and the chi-square test for independent groups were used in the bivariate analysis. Paired tests were also used to evaluate the before-after differences for each subgroup (McNemar's test and the Student's $t$ test). A survival analysis was made by estimating the Kaplan-Meier curves (log-rank test) to analyze the persistence of opioid treatment, applying a Cox proportional risk model (corrected by covariates) to determine the hazard ratio (HR) and its $95 \% \mathrm{Cl}$ between strong and weak opioids. Covariate analysis was used to correct the cost per patient of days of sick leave. The covariates included were sex, age, general comorbidity (Charlson index), time from diagnosis, treatment persistence and the MPR. A multiple linear regression model (procedure: consecutive steps) was constructed to examine the variables associated with sick leave (dependent variable: cost per patient [all] of sick leave). The analyses used IBM SPSS, version 23.0, NY, USA software (https://www.ibm.com/analytics/spss-statistics-software).

\section{Results}

Of an initial selection of $1,280,684$ subjects aged $\geq 18$ years who sought care during the recruitment period, 124,798 were diagnosed with OA in any site with nociceptive pain of $>3$ months duration (chronic pain). Of these patients, $34 \%$ initiated a new opioid treatment $(n=42,429)$, who were the sample included in the OPIOIDS study. For the present analysis, 37,340 subjects $(77.2 \%)$ who were not active workers were excluded. Finally, 5,089 patients who met the study selection criteria were included (Figure 1). Table 1 shows the demographic characteristics and overall comorbidity; the mean age was 56.8 (SD: 4.6) years and $56.6 \%$ were male. Only 14 patients were aged $\geq 65$ years: $73.3 \%(n=3,732)$ initiated treatment with a weak opioid and $26.7 \%(n=1,357)$ with a strong opioid. Patients receiving strong opioids had greater comorbidity (Charlson index: 1.2 vs. $1.1 ; p=0.041$ ). The type of opioid medication administered and the medical specialty initiating the prescription are described in Supplementary table S1. Almost all prescriptions for weak opioids were for tramadol or tramadol + acetaminophen (98.1\%) while fentanyl, tapentadol and oxycodone-naloxone were the most frequently prescribed strong opioids $(76.4 \%)$. Strong opioids were proportionately more frequently prescribed by specialists than by GPs ( $40.6 \%$ vs. $22.6 \%$, $\mathrm{p}<0.001)$. Supplementary table $\mathrm{S} 2$ shows the concomitant medication prescribed by group and follow-up periods. During the 12 months before initiation of opioids, mean concomitant medication was 1.4 analgesics per patient compared with 1.2 at 36 months $(p<0.001)$. The reduction was mainly due to the 
lower use of acetaminophen alone ( $73 \%$ vs. $38.9 \%$, $p<0.001)$, which was compensated for by the significant increase in the use of NSAIDs and metamizole concomitantly with opioids (Supplementary table S2).

Treatment adherence, persistence, MPR, reasons for discontinuation and mortality by study group (strong/weak opioids) are shown in table 2. The median duration of opioid treatment was 187 days (interquartile range: $84-738$ days). At 36 months, overall treatment adherence was $21 \%$ (95\% Cl: $19.9 \%-22.1 \%$ ) and was $23 \%$ (95\% Cl: $21.6-24.4 \%$ ) for weak opioids and $15.4 \%$ (95\% Cl: $13.5-17.3 \%)$ for strong opioids $(p<0.001)$. Supplementary figure $S 1$ shows the Kaplan-Meier curves for the persistence of opioid treatment, with a corrected mean that was $27 \%$ higher for weak compared with strong opioids $(H R=1.27$ [1.17-1.34], $p=0.001)$. Pain intensity decreased significantly, but moderately $(-1.2$ points [-14\%], $p<0.001$ ), with only $6.8 \%$ of patients stopping opioids having no moderate or severe pain (Supplementary table S3). Pain reduction was greater in patients on weak opioids in comparison with those receiving strong opioids. Rehabilitation sessions showed no significant changes in the percentage of patients using this resource or in the mean number of rehabilitation sessions per patient according to both the period of the study or the type of opioid medications used (Supplementary figure S2), although a numeric increase in the percentage of rehabilitation user throughout the follow up of the study was observed.

Table 3 shows the distribution of days of sick leave and their cost by opioid type and study periods. Compared to the 12 months pre-opioid, during the following 12 months there were $4.3 \%$ more patients with sick leave $(\mathrm{p}<0.001)$, with a longer duration of sick leave, both in patients on sick leave and in the overall sample; 4.5 and 4.0 days, respectively $(p<0.001)$, which was accompanied by a significant increase in the cost of lost work productivity in the first year of opioid treatment; $€ 559$ and $€ 481$, respectively $(p<0.001)$ to $€ 6,837$ and $€ 2,594$ per patient, in the overall sample and in patients with sick leaves respectively, after 12 months of starting opioid therapy. The increase in the cost of sick leave was slightly higher in patients receiving weak opioids. At 12 months after initiation of opioid treatment, 37.9\% of patients had $\geq 1$ days of sick leave ( $6.1 \% \geq 6$ months), with a mean of 57.1 (SD: 55.3$)$ days/year in patients with sick leave and 21.7 (SD: 43.9) days/year overall. Patients receiving strong opioids had a longer duration of sick leave and a higher cost per patient than those receiving weak opioids. Table 3 also shows the evolution of the number of sick leaves and days of sick leave and their cost over the 36-month follow up.

Table 4 shows the cost per patient during the 36-month follow up, according to the different scenarios dependent on location of OA, pain reduction after opioid administration and concomitant use of NSAIDs. Patients with a relevant reduction of pain $\geq 50 \%$ of the pre-opioid severity of pain had a lower cost of sick leave in comparison to those who did not, while patients treated with strong opioids, regardless of whether or not they received concomitant NSAIDs, had a higher mean cost. In the multiple linear regression model, the mean cost of days of sick leave was associated with age $(\beta=0.043 ; p=0.003)$, female sex $(\beta=0.035, p=0.012)$, the severity of comorbidity $(\beta=0.034, p=0.018)$ and treatment with strong opioids $(\beta=0.037, p=0.011)$. Figure 2 shows the mean cost per patient of days of sick leave adjusted by covariates during the follow-up period according to sex and age group. The cost of sick leave was 
significantly higher in women and in individuals 55 or more years in comparison with men or younger patients, either receiving weak or strong opioids. In all subgroups, patients treated with strong opioids, regardless of sex or age group, showed higher cost per patient.

\section{Discussion}

This study was an analysis of a secondary endpoint of the OPIOIDS study in usual medical practice in Spain [20]. Active workers with OA who started opioid treatment for moderate/severe chronic pain showed high job productivity losses due to days of temporary occupational disability. Opioid use had low treatment adherence and early medication discontinuation, did not reduce previous levels of sick leave, and had a modest impact on pain reduction in the present research. There were also no significant differences in the use of rehabilitation by workers on sick leave compared to those without, highlighting the need for rehabilitation in these patients as noted above [27]. In addition, older age, female sex, the severity of comorbidity, and the use of strong opioids were associated with greater occupational costs because of higher number of workdays off due to temporary disability. There is a scarcity of observational studies in real-world conditions in the literature consulted, which makes it difficult to compare the results, but which enhances the singularity of the study and also the possibility of helping health authorities and opinion leaders when making healthcare decisions in OA patients. Standard randomized clinical trials should be used with caution for justification of political, medico-legal, and economic decisions as well as generalizing the results; outcomes obtained under routine medical care, like the ones includes here, could be of help to healthcare decision makers in OA. This is because such naturalistic, non-interventional studies may be complementary to evidence-based medicine supported by traditional clinical trial research $[28,29]$. In addition, the large number of patients included, together with the monitoring period analyzed, may support the degree of external validity of the results in Spain, and may be considered as a strength of the study.

In this study of active workers, the mean age was approximately 57 years and $56.6 \%$ were male, results consistent with those of other studies in patients with common musculoskeletal disorders $[14,16,17]$. After 36 months of follow up, treatment adherence was low (21\%). Kostev found that in a large cohort of patients ( $n=32,158)$ with chronic pain [30], adherence to opioids was low; $69 \%$ of patients discontinued treatment per year of follow up, similar to our study (64\%). In the series analyzed in this research, opioid use did not result in a substantial reduction in pain and had no direct effect in reducing days of sick leave. Our results show a close relationship between pain intensity and days of sick leave. Reducing days of sick leave would require a multidisciplinary approach, including improvements in pain (new treatments), associated comorbidity (obesity, psychological states), lifestyle and/or occupational conditions (occupational risk of certain jobs). We found that, in one-third of patients, there was a significant impact of lost productivity per follow-up year, which increased to $77 \%$ at the end of the follow up. These results are in line with other reports [14]. For each follow-up year, there was a mean sick leave in patients on sick leave of 57.1 days/year; in $8.2 \%$ of patients the mean was $1-7$ days and in $6.1 \%$ it was $\geq 6$ months while, in all patients, the mean was 21.7 days/year at a cost of $€ 2,594 /$ year/patient. At 36 
months, $77 \%$ of patients had taken some days of sick leave, with a mean of lost working days of 93 days, and of $\geq 6$ months in $16.9 \%$ of patients, at a cost of $€ 11,103 /$ patient.

Different designs and time periods and the lack of specific studies make it difficult to compare the results. Hubertsson et al., analyzed patients aged 16-64 years and found that sick leave was more common in the 50-64 years age group and differed between males and females [17]. For lower back pain and myalgia, $27 \%$ and $26 \%$ of all sick leaves were short (8-14 days) and only $11 \%$ and $13 \%$ were long ( $\geq 90$ days). Berger found that private sector employees with OA had a mean of 62.9 days of sick leave compared with 36.7 days in a control group without OA [31]. Mean total indirect costs were twice as high in patients with $O A(\$ 5,002$ vs. $\$ 2,120)$. Pekkala highlighted the hierarchical differences in occupational classes between different musculoskeletal disorders [32], with large discrepancies in back and shoulder disorders. Rabenda and coworkers [33], in a cohort of active workers, underlined the high burden of direct and indirect costs of patients with $\mathrm{OA}(€ 15.2$ and $€ 23.8$, respectively, per active subject per month; equivalent to 0.8 days of sick leave per patient per month), which were predominantly productivity-related costs. Mather found that $10.8 \%$ of days of sick leave were $\geq 90$ days/year [34]. Some reports have concluded that an increase in sick leave and its cost as a result of $O A$ is expected in forthcoming years [14]. Taking methodological differences into account, our results are broadly in line with these studies.

The association with strong opioids may be motivated by a greater degree of severity of OA or associated comorbidities. Some authors are studied previously the association of opioid use and days off work and found a relationship between taking opioids, both weak or strong, and disability to work. Lalic and coworkers [35], found that among the $6.9 \%$ of people initiating strong opioids, $12.5 \%$ had persistent high sickness absence and disability pension (estimated 320 days/year) before and after opioid initiation and $72.9 \%$ had persistent low/minimum sickness absence and disability pension (estimated 30 days/year).

Tao et al. reported a significant association of the use of opioid and psychotropic medications with workers' compensation claim costs and prolonged disability. In general, it is assumed that opioid abuse/dependence impose a substantial economic burden on employers [36-37].

The possible limitations of the study are those inherent to retrospective studies (under recording, coding errors, variations in professionals and patients and possible classification bias). In addition, the individual severity of $\mathrm{OA}$ or the interactions between different comorbidities were not considered. Neither could the associations between the intensity of chronic pain and days of sick leave be assessed because they were not available in the database (occupational risk control, work adaptation, flexibility of schedules, etc.), although this should not have influenced the study results.

\section{Conclusions}

In usual clinical practice in Spain, active workers who started opioid treatment for moderate to severe chronic OA pain showed high costs due to days of sick leave, with a modest reduction in pain. Age, female sex, severity of comorbidity and the use of strong opioids were significantly associated with the cost of lost occupational productivity. 


\section{Declarations}

\section{Availability of data and materials}

he datasets (aggregated and anonymized), analyzed for the elaboration of this specific study, are available (on reasonable request) at the following email address: ansicras@atryshealth.com.

\section{Acknowledgements}

Not applicable.

\section{Funding}

The study was funded by Pfizer, SLU.

\section{Contributions}

The study was conceived by ASM (ansicras@atryshealth.com),JRG (javier.rejas@pfizer.com) and IL (Isabel.lizarraga@pfizer.com). ASM, CTT (carlostornero @gmail.com), FVN (fvargasnegrin@gmail.com), JRG, ASN (arsicras@atryshealth.com) and IL participated and contributed to the study design. Data collection and the statistical analysis were made by ASM and ASN. Data interpretation of data was made by all authors. All authors drafted or critically revised and approved the final version of the submitted manuscript.

\section{Corresponding author}

Antoni Sicras-Mainar (ansicras@atryshealth.com; orcid.org/0000-0002-8232-293X)

\section{Ethics approval and consent to participate}

The OPIOIDS study was classified by the Spanish Agency for Medicines and Health Products and approved by the Ethics Committee of the Hospital of Terrassa (Barcelona). The Strengthening the Reporting of Observational Studies in Epidemiology (STROBE) statement guidelines for reporting observational studies were followed.

\section{Consent for publication}

Not applicable.

\section{Competing interests}

Antoni Sicras-Mainar and Aram Sicras-Navarro are employees of Atrys Health SA, who were paid consultants to Pfizer in connection with this manuscript. Javier Rejas-Gutiérrez and Isabel Lizarraga are employees of Pfizer, SLU. Carlos Tornero-Tornero and Francisco Vargas-Negrín declare no competing interests. 


\section{References}

1. Kolasinski SL, Neogi T, Hochberg MC, Oatis C, Guyatt G, Block J, et al. 2019 American College of Rheumatology/Arthritis Foundation Guideline for the Management of Osteoarthritis of the Hand, Hip, and Knee. Arthritis Rheumatol. 2020; 72(2):220-33.

2. Pereira D, Peleteiro B, Araújo J, Branco J, Santos RA, Ramos E. The effect of osteoarthritis definition on prevalence and incidence estimates: a systematic review. Osteoarthritis Cartilage. 2011; 19:127085.

3. O'Neill TW, McCabe PS, McBeth J. Update on the epidemiology, risk factors and disease outcomes of osteoarthritis. Best Pract Res Clin Rheumatol. 2018; 32:312-26.

4. Blanco FJ, Silva-Díaz M, Quevedo Vila V, Seoane-Mato D, Pérez Ruiz F, Juan-Mas A, et al. on behalf of the Grupo of Trabajo del Proyecto EPISER2016. Prevalence of symptomatic osteoarthritis in Spain: EPISER2016 study. Reumatol Clin. 2020. doi: 10.1016/j.reuma.2020.01.008.

5. Kroon FPB, Carmona L, Schoones JW, Kloppenburg M. Efficacy and safety of non-pharmacological, pharmacological and surgical treatment for hand osteoarthritis: a systematic literature review informing the 2018 update of the EULAR recommendations for the management of hand osteoarthritis. RMD Open. 2018;4(2): e000734.

6. Majeed MH, Sherazi SAA, Bacon D, Bajwa ZH. Pharmacological Treatment of Pain in Osteoarthritis: A Descriptive Review. Curr Rheumatol Rep. 2018;20(12):88.

7. O'Neil CK, Hanlon JT, Marcum ZA. Adverse effects of analgesics commonly used by older adults with osteoarthritis: focus on non-opioid and opioid analgesics. Am J Geriatr Pharmacother. 2012;10(6):331-42.

8. Yip K, Oettinger J. Why are we still using opioids for osteoarthritis? Int J Clin Pract. 2020;74(1): e13416.

9. Bannuru RR, Osani MC, Vaysbrot EE, Arden NK, Bennell K, Bierma-Zeinstra SMA, et al. OARSI guidelines for the non-surgical management of knee, hip, and polyarticular osteoarthritis. Osteoarthritis Cartilage 2019; 27: 1578-89.

10. McDonough CM, Jette AM. The contribution of osteoarthritis to functional limitations and disability. Clin Geriatr Med. 2010; 26(3):387-99.

11. Xie F, Kovic B, Jin X, He X, Wang M, Silvestre C. Economic and Humanistic Burden of Osteoarthritis: A Systematic Review of Large Sample Studies. Pharmacoeconomics. 2016; 34(11):1087-100.

12. Hermans J, Koopmanschap MA, Bierma-Zeinstra SM, van Linge JH, Verhaar JA, Reijman M, et al. Productivity costs and medical costs among working patients with knee osteoarthritis. Arthritis Care Res (Hoboken). 2012; 64(6):853-61.

13. Puig-Junoy J, Ruiz Zamora A. Socio-economic costs of osteoarthritis: a systematic review of cost-ofillness studies. Semin Arthritis Rheum. 2015; 44(5):531-41.

14. Sharif B, Garner R, Hennessy D, Sanmartin C, Flanagan WM, Marshall DA. Productivity costs of work loss associated with osteoarthritis in Canada from 2010 to 2031. Osteoarthritis Cartilage. 2017; 
25(2):249-58.

15. Wilkie R, Hay EM, Croft P, Pransky G. Exploring how pain leads to productivity loss in primary care consulters for osteoarthritis: a prospective cohort study. PLoS One. 2015;10(4): e0120042.

16. Berger A, Hartrick C, Edelsberg J, Sadosky A, Oster G. Direct and indirect economic costs among private-sector employees with osteoarthritis. J Occup Environ Med 2011;53(11):1228e35.

17. Hubertsson J, Englund M, Hallgårde U, Lidwall U, Löfvendahl S, Petersson IF. Sick leave patterns in common musculoskeletal disorders -a study of doctor-prescribed sick leave. BMC Musculoskelet Disord. 2014; 15:176.

18. Alamanda VK, Wally MK, Seymour RB, Springer BD, Hsu JR; Prescription Reporting With Immediate Medication Utilization Mapping Group. Prevalence of Opioid and Benzodiazepine Prescriptions for Osteoarthritis. Arthritis Care Res (Hoboken). 2020;72(8):1081-86.

19. Ministerio of Sanidad, Servicios Sociales e Igualdad. Utilización of medicamentos opioides en España durante el periodo 2010-2018. https://www.aempgob.es/medicamentos-of-usohumano/observatorio-of-uso-of-medicamentos/utilizacion-of-medicamentos-opioides-en-espanadurante-el-periodo-2010-2018. Accessed: January 2020.

20. Sicras-Mainar A, Tornero-Tornero C, Vargas-Negrín F, Lizarraga I, Rejas-Gutierrez Health outcomes and costs in patients with osteoarthritis and chronic pain treated with opioids in Spain: The OPIOIDS Real World study. Ther Adv Musculoskelet Dis. 2020; 12: 1-18.

21. Sicras-Mainar A, Enríquez JL, Hernández I, Sicras-Navarro A, Aymerich T, León M. Validation and representativeness of the Spanish BIG-PAC database: integrated computerized medical records for research into epidemiology, medicines and health resource use (Real Word Evidence). Value Health. 2019;(Supplement 3): S734.

22. von Elm E, Altman DG, Egger M, Pocock SJ, Gøtzsche PC, Vandenbroucke JP. STROBE Initiative. The Strengthening the Reporting of Observational Studies in Epidemiology (STROBE) statement: guidelines for reporting observational studies. J Clin Epidemiol. 2008;61(4):344-9.

23. Vicente Herrero MT, Delgado Bueno S, Bandrés Moyá F, Ramírez Iñiguez of la Torre MV, Capdevila García L. Valoración del dolor. Revisión comparativa of escalas y cuestionarios. Rev Soc Esp Dolor. 2018; 25:228-36.

24. The Anatomical Therapeutic Chemical Classification System with Defined Daily Doses (ATC/DDD): World Health Organization. Available at: https://www.who.int/ classifications/atcddd/en/. Accessed: 09/08/2020.

25. Charlson ME, Pompei P, Ales KL, Mackenzie CR. A new method of classifying prognostic comorbidity in longitudinal studies: development and validation. J Chronic Dis. 1987; 40:373-83.

26. Instituto Nacional of Estadística (INE). Salarios y costes laborales 2018. https://www.ine.es/dyngs /INEbase/es/. Accessed: August 2020.

27. Gobelet C, Luthi F, Al-khodairy AT, Chamberlain MA. Work in inflammatory and degenerative joint diseases. Disability and Rehabilitation. 2007; 29(17): 1331-39. 
28. Mielke D, Rohde V. Randomized controlled trials-a critical re-appraisal. Neurosurg Rev. 2020. doi: 10.1007/s10143-020-01401-4.

29. Bothwell LE, Greene JA, Podolsky SH, Jones DS. Assessing the gold standard - lessons from the history of RCTs. N Engl J Med. 2016; 374:2175-81.

30. Kostev K, Wartenberg F, Richter H, Reinwald M, Heilmaier C. Persistence with opioid treatment in Germany in patients suffering from chronic non-malignant or cancer pain. Curr Med Res Opin. 2015; 31:1157-63.

31. Berger A, Hartrick C, Edelsberg J, Sadosky A, Oster G Direct and indirect economic costs among private-sector employees with osteoarthritis. J Occup Environ Med. 2011;53(11):1228-35.

32. Pekkala J, Rahkonen O, Pietiläinen O, Lahelma E, Blomgren J. Sickness absence due to different musculoskeletal diagnoses by occupational class: a register-based study among 1.2 million Finnish employees. Occup Environ Med. 2018;75(4):296-302.

33. Rabenda V, Manette C, Lemmens R, Mariani AM, Struvay N, Reginster JY. Direct and indirect costs attributable to osteoarthritis in active subjects. J Rheumatol. 2006; 33(6):1152-8.

34. Mather L, Ropponen A, Mittendorfer-Rutz E, Narusyte J, Svedberg P. Health, work and demographic factors associated with a lower risk of work disability and unemployment in employees with lower back, neck and shoulder pain. BMC Musculoskelet Disord. 2019; 20(1):622.

35. Lalic S, Bell JS, Gyllensten H, Gisev N, Friberg E, llomaki J, et al. Trajectories of sickness absence and disability pension before and after opioid initiation for noncancer pain: a 10-year population-based study. 2019;160(5):1224-33.

36. Tao XG, Lavin RA, Yuspeh L, Weaver VM, Bernacki EJ, Tao XG, et al. The association of the use of opioid and psychotropic medications with workers' compensation claim costs and lost work time. J Occup Environ Med. 2015;57(2):196-201.

37. Rice JB, Kirson NY, Shei A, Cummings AK, Bodnar K, Birnbaum HG, et al. Estimating the costs of opioid abuse and dependence from an employer perspective: a retrospective analysis using administrative claims data. Appl Health Econ Health Policy. 2014;12(4):435-46.

\section{Tables}

Table 1. Baseline characteristics (demographic and morbidity) of patients by study groups. 


\begin{tabular}{|c|c|c|c|c|}
\hline Study groups & Weak opioid & Strong Opioid & Total & \multirow{2}{*}{$\begin{array}{l}\mathrm{p}- \\
\text { value }\end{array}$} \\
\hline Number of patients, \% & $\begin{array}{l}N=3732 \\
(73.3 \%)\end{array}$ & $\begin{array}{l}N=1357 \\
(26.7 \%)\end{array}$ & $\begin{array}{l}N=5089 \\
(100 \%)\end{array}$ & \\
\hline \multicolumn{5}{|l|}{ Demographic features } \\
\hline Mean age, years (SD) & $56.8(4.6)$ & $56.8(4.7)$ & $56.8(4.6)$ & 0.848 \\
\hline Age group: 18 - 44 years & $1.4 \%$ & $1.4 \%$ & $1.4 \%$ & \\
\hline $45-54$ years & $33.8 \%$ & $33.2 \%$ & $33.6 \%$ & \\
\hline$\geq 55$ years & $64.8 \%$ & $65.4 \%$ & $65.0 \%$ & 0.912 \\
\hline Sex (female & $56.2 \%$ & $57.5 \%$ & $56.6 \%$ & 0.431 \\
\hline \multicolumn{5}{|l|}{ General comorbidity } \\
\hline Mean diagnoses (SD) & $2.3(1.5)$ & $2.4(1.6)$ & $2.4(1.6)$ & 0.032 \\
\hline Mean Charlson index (SD) & $1.1(0.3)$ & $1.2(0.3)$ & $1.1(0.3)$ & 0.041 \\
\hline 0 & $44.6 \%$ & $47.5 \%$ & $45.4 \%$ & \\
\hline 1 & $27.5 \%$ & $22.5 \%$ & $26.2 \%$ & \\
\hline 2 & $13.8 \%$ & $16.0 \%$ & $14.4 \%$ & \\
\hline $3+$ & $6.0 \%$ & $6.6 \%$ & $6.2 \%$ & 0.066 \\
\hline \multicolumn{5}{|l|}{ Associated comorbidities } \\
\hline High blood pressure & $39.8 \%$ & $39.1 \%$ & $39.6 \%$ & 0.683 \\
\hline Diabetes & $16.6 \%$ & $16.9 \%$ & $16.7 \%$ & 0.807 \\
\hline Dyslipidemia & $55.3 \%$ & $52.5 \%$ & $54.5 \%$ & 0.078 \\
\hline Obesity & $29.0 \%$ & $23.0 \%$ & $27.4 \%$ & $<0.001$ \\
\hline Ischemic heart disease & $4.5 \%$ & $4.3 \%$ & $4.5 \%$ & 0.783 \\
\hline Cerebrovascular event & $2.8 \%$ & $3.8 \%$ & $3.1 \%$ & 0.084 \\
\hline Heart failure & $1.8 \%$ & $2.9 \%$ & $2.1 \%$ & 0.017 \\
\hline Kidney failure & $1.9 \%$ & $1.8 \%$ & $1.9 \%$ & 0.710 \\
\hline Asthma & $11.3 \%$ & $11.3 \%$ & $11.3 \%$ & 0.967 \\
\hline COPD & $7.2 \%$ & $7.8 \%$ & $7.3 \%$ & 0.426 \\
\hline Dementia & $1.3 \%$ & $2.3 \%$ & $1.6 \%$ & 0.017 \\
\hline Depressive syndrome & $20.3 \%$ & $23.3 \%$ & $21.1 \%$ & 0.023 \\
\hline Anxiety & $46.8 \%$ & $50.6 \%$ & $47.8 \%$ & 0.018 \\
\hline
\end{tabular}




\begin{tabular}{|lllll|}
\hline Malignancies & $5.8 \%$ & $5.4 \%$ & $5.7 \%$ & 0.554 \\
\hline Osteoporosis & $19.6 \%$ & $21.9 \%$ & $20.2 \%$ & 0.071 \\
\hline Lifestyle & & & & \\
\hline Active smokers (daily) & $23.6 \%$ & $27.7 \%$ & $24.7 \%$ & 0.003 \\
\hline $\begin{array}{l}\text { Alcohol consumption } \geq 30 \\
\text { grams/day }\end{array}$ & $2.8 \%$ & $2.4 \%$ & $2.7 \%$ & 0.521 \\
\hline Osteoarthritis site & & & & \\
\hline Knee/hip & $49.8 \%$ & $49.4 \%$ & $49.7 \%$ & \\
\hline Spine & $31.5 \%$ & $32.1 \%$ & $31.7 \%$ & \\
\hline Others & $18.6 \%$ & $18.6 \%$ & $18.6 \%$ & 0.939 \\
\hline
\end{tabular}

Values expressed as percentage or mean (SD: standard deviation). COPD: chronic obstructive pulmonary disease.

Table 2. Treatment persistence and adherence, medication possession ratio and discontinuation by study groups. 


\begin{tabular}{|c|c|c|c|c|}
\hline Study groups & Weak opioid & Strong Opioid & Total & \multirow{2}{*}{$\begin{array}{l}\mathrm{p}- \\
\text { value }\end{array}$} \\
\hline Number of patients, $\%$ & $\begin{array}{l}N=3732 \\
(73.3 \%)\end{array}$ & $\begin{array}{l}N=1357 \\
(26.7 \%)\end{array}$ & $\begin{array}{l}N=5089 \\
(100 \%)\end{array}$ & \\
\hline Time from diagnosis, years & $3.4(1.0)$ & $3.5(1.2)$ & $3.4(1.1)$ & 0.002 \\
\hline - Median (P25 - P75) & $2.9(2.7-3.9)$ & $2.9(2.7-3.8)$ & $2.9(2.7-3.9)$ & \\
\hline Duration of treatment, days & $427(417.4)$ & $343.4(372.9)$ & $404.7(407.7)$ & $<0.001$ \\
\hline - Median (P25 - P75) & $201(84-890)$ & $155(83-467)$ & $187(84-738)$ & \\
\hline \multicolumn{5}{|l|}{ Medication possession ratio } \\
\hline Percentage & $74.0 \%$ & $69.2 \%$ & $72.7 \%$ & $<0.001$ \\
\hline $95 \% \mathrm{Cl}$ & $72.6-75.4 \%$ & $66.7-71.7 \%$ & $71.5-73.9 \%$ & \\
\hline \multicolumn{5}{|l|}{ Treatment adherence (\%) } \\
\hline 12 months & $38.6 \%$ & $29.0 \%$ & $36.0 \%$ & $<0.001$ \\
\hline $95 \% \mathrm{Cl}$ & $37.0-40.2 \%$ & $26.6-31.4 \%$ & $34.7-37.3 \%$ & \\
\hline 24 months & $27.4 \%$ & $18.6 \%$ & $25.1 \%$ & $<0.001$ \\
\hline $95 \% \mathrm{Cl}$ & $26.0-28.8 \%$ & $16.5-20.7 \%$ & $23.9-26.3 \%$ & \\
\hline 36 months & $23.0 \%$ & $15.4 \%$ & $21.0 \%$ & $<0.001$ \\
\hline $95 \% \mathrm{Cl}$ & $21.6-24.4 \%$ & $13.5-17.3 \%$ & $19.9-22.1 \%$ & \\
\hline Discontinuation (\%) & $77.0 \%$ & $84.6 \%$ & $79.0 \%$ & $<0.001$ \\
\hline Poor tolerability* & $11.8 \%$ & $8.7 \%$ & $10.9 \%$ & 0.004 \\
\hline $95 \% \mathrm{Cl}$ & $10.8-12.8 \%$ & $7.2-10.2 \%$ & $10.0-11.8 \%$ & \\
\hline Poor response ${ }^{\star \star}$ & $48.2 \%$ & $60.4 \%$ & $51.7 \%$ & $<0.001$ \\
\hline $95 \% \mathrm{Cl}$ & $46.6-49.8 \%$ & $57.8-63.0 \%$ & $50.3-53.1 \%$ & \\
\hline $\begin{array}{l}\text { Change from weak to strong } \\
\text { opioid }\end{array}$ & $17.3 \%$ & NA & NA & NA \\
\hline $95 \% \mathrm{Cl}$ & $16.1-18.5 \%$ & & & \\
\hline Other changes ${ }^{\star \star \star}$ & $12.5 \%$ & $21.3 \%$ & $15.0 \%$ & $<0.001$ \\
\hline $95 \% \mathrm{Cl}$ & $11.4-13.6 \%$ & $19.1-23.5 \%$ & $14.0-16.0 \%$ & \\
\hline Lost-to-follow up & $10.1 \%$ & $9.6 \%$ & $10.0 \%$ & 0.601 \\
\hline $95 \% \mathrm{Cl}$ & $9.1-11.1 \%$ & $8.8-11.2 \%$ & $9.2-10.8 \%$ & \\
\hline Any cause deaths & $1.1 \%$ & $3.1 \%$ & $1.7 \%$ & $<0.001$ \\
\hline
\end{tabular}


Values expressed as percentage or mean (standard deviation), Cl: confidence interval, P: percentile. NA: Not applicable. *Discontinuation after $1^{\text {st }}$ prescription dispensed in community pharmacy without refills during study follow-up; **Pain numeric rating scale $\geq 5$ points in last available measurement; ${ }^{* \star *}$ Other changes: includes patients with hospital admission for surgical procedures (joint replacement, arthroscopy, $2.6 \%)$, referrals to the pain clinic (1.3\%) and changes in non-opioid medication $(0.9 \%)$.

Table 3. Distribution of days of sick leave and annual cost due to lost productivity according to opioid type and study periods. 
Study groups

Number of patients. \%
Weak opioid

$\mathrm{N}=3732$

$(73.3 \%)$
Strong Opioid

$\mathrm{N}=1357$

(26.7\%)
Total

$\mathrm{N}=5089$

$(100 \%)$ pvalue

\section{2 months pre-opioid}

Patients with sick leave. \%

$33.4 \%$

$34.5 \%$

$33.7 \%$

0.452

Ranges according to days of sick leave

\begin{tabular}{|c|c|c|c|c|}
\hline 1 - 7 days & $15.3 \%$ & $13.7 \%$ & $14.9 \%$ & \\
\hline 8 - 14 days & $18.6 \%$ & $11.5 \%$ & $16.7 \%$ & \\
\hline 15 - 89 days & $51.9 \%$ & $56.8 \%$ & $53.2 \%$ & \\
\hline $90-181$ days & $11.0 \%$ & $13.9 \%$ & $11.8 \%$ & \\
\hline$\geq 182$ days ( 6 months) & $3.1 \%$ & $4.1 \%$ & $3.4 \%$ & 0.003 \\
\hline $\begin{array}{l}\text { Days of sick leave in patients with } \\
\text { sick leave }\end{array}$ & $49.9(48.6)$ & $59.6(52.4)$ & $52.6(49.8)$ & $<0.001$ \\
\hline Days of sick leave in all patients & $16.6(36.6)$ & $20.6(41.8)$ & $17.7(38.1)$ & 0.001 \\
\hline $\begin{array}{l}\text { Cost/year for patient with sick leave } \\
(€)\end{array}$ & $5960(5804)$ & $7122(6258)$ & $6277(5952)$ & $<0.001$ \\
\hline Cost/year for patient (all. €) & $1988(4374)$ & $2456(4996)$ & $2113(4552)$ & 0.001 \\
\hline \multicolumn{5}{|l|}{12 months post-opioid initiation } \\
\hline Patients with sick leave. \% & $38.2 \%$ & $37.4 \%$ & $37.9 \%$ & 0.605 \\
\hline
\end{tabular}

Ranges according to days of sick leave

\begin{tabular}{|c|c|c|c|c|}
\hline 1 - 7 days & $9.5 \%$ & $4.7 \%$ & $8.2 \%$ & \\
\hline 8 - 14 days & $15.3 \%$ & $10.7 \%$ & $14.1 \%$ & \\
\hline 15 - 89 days & $59.1 \%$ & $63.1 \%$ & $60.1 \%$ & \\
\hline 90 - 181 days & $10.5 \%$ & $14.2 \%$ & $11.5 \%$ & 0.160 \\
\hline$\geq 182$ days ( 6 months) & $5.6 \%$ & $7.3 \%$ & $6.1 \%$ & 0.001 \\
\hline $\begin{array}{l}\text { Days of sick leave in patients with } \\
\text { sick leave }\end{array}$ & $54.6(54.1)$ & $64.2(58.1)$ & $57.1(55.3)$ & 0.004 \\
\hline Days of sick leave in all patients & $20.9(42.7)$ & $24.0(47.2)$ & $21.7(43.9)$ & 0.027 \\
\hline $\begin{array}{l}\text { Cost/year for patient with sick leave } \\
(€)\end{array}$ & $6541(6458)$ & 7666 (6939) & $6837(6604)$ & 0.004 \\
\hline Cost/year for patient (all. €) & $2496(5100)$ & $2864(5633)$ & $2594(5249)$ & 0.027 \\
\hline
\end{tabular}


Variations in 12 months before and 12 months after opioid initiation

Patients with sick leave (\%. 95\% Cl)

$$
\begin{array}{llll}
4.8 \%(4.1-5.5)^{\ddagger} & 2.9 \%(2.0-3.8) & \begin{array}{l}
\text { 出.3\% (3.7-4.9) } \\
\ddagger
\end{array} & 0.007
\end{array}
$$

Days of sick leave in patients with sick leave

$4.7(3.1-6.3)^{\ddagger} \quad 4.6(2.6-6.6)^{\ddagger} \quad 4.5(2.6-6.4)^{\ddagger} \quad 0.654$

Days of sick leave in all patients

$4.3(2.5-6.1)^{\ddagger}$

$3.4(0.2-5.8)$ *

$4.0(2.4-5.6)^{\ddagger}$

0.455

Cost/year for patient with sick leave $(€)$

$581(578-585) \quad 544(539-$

$\neq$

$548)^{*}$

559 (556$<0.001$

Cost/year for patient (all. €)

$508(458-555)$

408 (326-

$489)^{*}$

$561)^{\ddagger}$

$481(439-$ $<0.001$ ‡

\section{6 months post-opioid initiation}

Patients with sick leave. \%

$77.6 \%$

$75.5 \%$

$77.0 \%$

0.109

Range/ intervals

\begin{tabular}{|c|c|c|c|c|}
\hline 1 - 7 days & $4.9 \%$ & $0.5 \%$ & $3.8 \%$ & \\
\hline $8-14$ days & $11.6 \%$ & $2.2 \%$ & $9.2 \%$ & \\
\hline 15 - 89 days & $63.7 \%$ & $66.4 \%$ & $64.4 \%$ & \\
\hline $90-181$ days & $3.1 \%$ & $13.5 \%$ & $5.8 \%$ & \\
\hline$\geq 182$ days ( 6 months) & $16.7 \%$ & $17.4 \%$ & $16.9 \%$ & $<0.001$ \\
\hline $\begin{array}{l}\text { Days of sick leave in patients with } \\
\text { sick leave }\end{array}$ & $115.5(179.1)$ & $134.5(188.8)$ & $120.5(181.8)$ & 0.004 \\
\hline Days of sick leave in all patients & $89.8(165.2)$ & $101.6(173.9)$ & $93.0(167.6)$ & 0.026 \\
\hline $\begin{array}{l}\text { Cost/year for patient with sick leave } \\
(€)\end{array}$ & $13823(21421)$ & $\begin{array}{l}16084 \\
(22548)\end{array}$ & $\begin{array}{l}14414 \\
(21741)\end{array}$ & 0.004 \\
\hline Cost/year for patient (all. €) & 10727 (19731) & $\begin{array}{l}12137 \\
(20773)\end{array}$ & $\begin{array}{l}11103 \\
(20021)\end{array}$ & 0.026 \\
\hline \multicolumn{5}{|l|}{ Sick leaves during follow up } \\
\hline 0 (none) & $22.4 \%$ & $24.5 \%$ & $23.0 \%$ & \\
\hline 1 & $35.9 \%$ & $29.9 \%$ & $34.3 \%$ & \\
\hline 2 & $24.2 \%$ & $29.4 \%$ & $25.6 \%$ & \\
\hline $3+$ & $17.5 \%$ & $16.1 \%$ & $17.2 \%$ & $<0.001$ \\
\hline
\end{tabular}


Values expressed as percentage or mean (95\% confidence interval), mean (95\%) cost expressed in $€$. ${ }^{\ddagger} p<0.001 ;{ }^{\dagger} p<0.01 ;{ }^{*} p<0.05$. Non-significant when not indicated.

Table 4. Mean cost per patient $(\epsilon)$ of sick leave adjusted by covariates during the follow up ( 36 months) in different scenarios and associated factors. 


\begin{tabular}{|c|c|c|c|}
\hline Scenario & $\begin{array}{l}\text { Cost/patient-year* } \\
(95 \% \mathrm{Cl})\end{array}$ & Difference $(95 \% \mathrm{Cl})$ & $\begin{array}{l}\mathrm{p}- \\
\text { value }\end{array}$ \\
\hline \multicolumn{4}{|l|}{ Site of osteoarthritis } \\
\hline Knee/hip & $11,576(10,609-12,544)$ & $\begin{array}{l}\text { vs. Spine;874 (-1,029- } \\
2,777)\end{array}$ & 0.869 \\
\hline Spine & $10,702(9,480-11,923)$ & $\begin{array}{l}\text { vs. other; } 360(-2,620- \\
1,901)\end{array}$ & 0.781 \\
\hline Other & $11,936(10,359-13,513)$ & $\begin{array}{l}\text { vs. other; } 1,234(-2,578- \\
110)\end{array}$ & 0.517 \\
\hline \multicolumn{4}{|l|}{ Type of opioid } \\
\hline Weak opioid & $10,987(10,218-11,756)$ & & \\
\hline Strong opioid & $12,516(10,985-14,048)$ & $1,529(188-3,255)$ & 0.044 \\
\hline \multicolumn{4}{|l|}{ Pain reduction (initial vs. final) } \\
\hline $\begin{array}{l}\text { Relative reduction in baseline pain } \\
\geq 30 \%\end{array}$ & $11,265(10,532-11,998)$ & & \\
\hline $\begin{array}{l}\text { Relative reduction in baseline pain } \\
<30 \%\end{array}$ & $11,983(10,081-13,885)$ & $718(-1,318-2,754)$ & 0.491 \\
\hline $\begin{array}{l}\text { Relative reduction in baseline pain } \\
\geq 50 \%\end{array}$ & $11,141(10,432-11,851)$ & & \\
\hline $\begin{array}{l}\text { Relative reduction in baseline pain } \\
<50 \%\end{array}$ & $14,016(11,471-16,561)$ & $2,875(232-5,518)$ & 0.033 \\
\hline Pain in last record $\geq 5$ in NRS & $11,282(10,572-11,993)$ & & \\
\hline Pain in last record $<5$ in NRS & $12,226(9,670-14,783)$ & $944(-1092-2262)$ & 0.459 \\
\hline \multicolumn{4}{|l|}{ Combinations of NSAIDs + opioids } \\
\hline Without NSAID + weak opioid & $10,724(9,872-11,578)$ & & \\
\hline Without NSAID + strong opioid & $12,258(10,645-13,872)$ & $1,534(188-2,881)$ & 0.042 \\
\hline With NSAID + weak opioid & $10,729(9,783-11,675)$ & & \\
\hline With NSAID + strong opioid & $12,018(10,498-13,538)$ & $1,289(57-2,635)$ & 0.046 \\
\hline Multiple linear regression model & $\begin{array}{l}\text { Standardized } \\
\text { coefficients }(\beta)\end{array}$ & $\mathrm{t}$ & $\mathrm{p}$ \\
\hline Age, years & 0.043 & 2.960 & 0.003 \\
\hline Sex (female) & 0.036 & 2.500 & 0.011 \\
\hline Charlson index (comorbidity) & 0.035 & 2.440 & 0.015 \\
\hline Strong opioid & 0.031 & 2.244 & 0.025 \\
\hline
\end{tabular}


Values expressed as percentage or mean (95\% Cl: 95\% confidence intervals), t: Student's t test.

* Analysis of covariance (ANCOVA; procedure: estimate of marginal means; Bonferroni adjustment), for adjustment of cost per patient of days of sick leave. Covariates: age, sex, time from diagnosis, Charlson index, treatment persistence and relative reduction in pain). NRS: Numeric rating scale of pain. NSAID: Nonsteroidal anti-inflammatory drug.

\section{Figures}


Missing/inconsistent data Outside study period - data base Excluded from prescription program Displaced/out of area

Terminal/institutionalized patients Cancer and other diseases Non-active workers, disabled/retired Permanent disability Unemployed Other reasons
Total population $\mathrm{n}=1.8$ million

Adults aged $\geq 18$ years

$1,469,710$

\section{Sought care}

Aged $\geq 18$ years (study period) $1,280,684$

Chronic nociceptive pain due to osteoarthritis

(NRS $\geq 5$ ) 124,798

Initiated treatment with opioids (study period) 42,429

\begin{tabular}{|c|} 
Patients excluded \\
1,949 \\
1,582 \\
892 \\
594 \\
676 \\
1,352 \\
28,845 \\
673 \\
394 \\
383 \\
\hline
\end{tabular}

\section{Patients recruited}

5,089

Weak opioid 3,732

\section{Figure 1}

Study flow diagram. NRS: numeric rating scale 
A) By sex

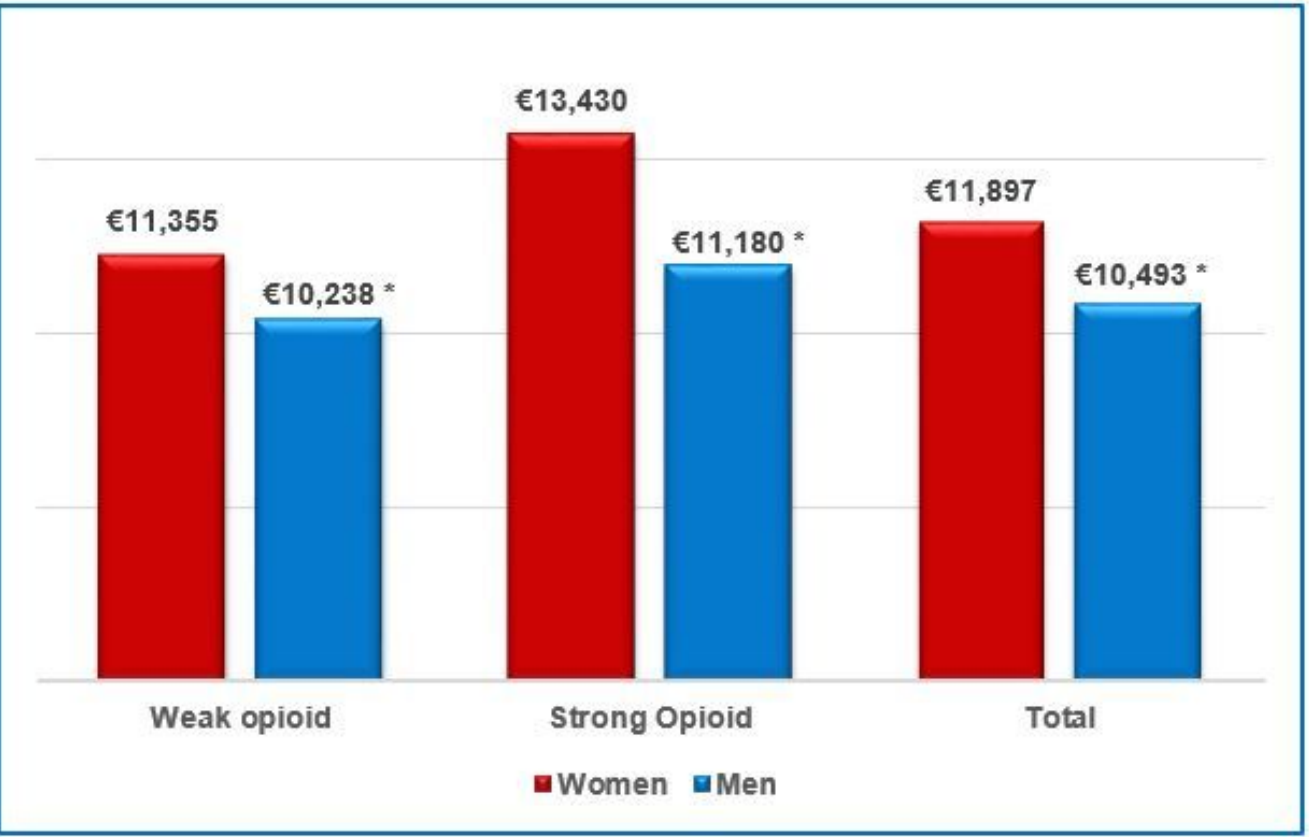

B) By age group

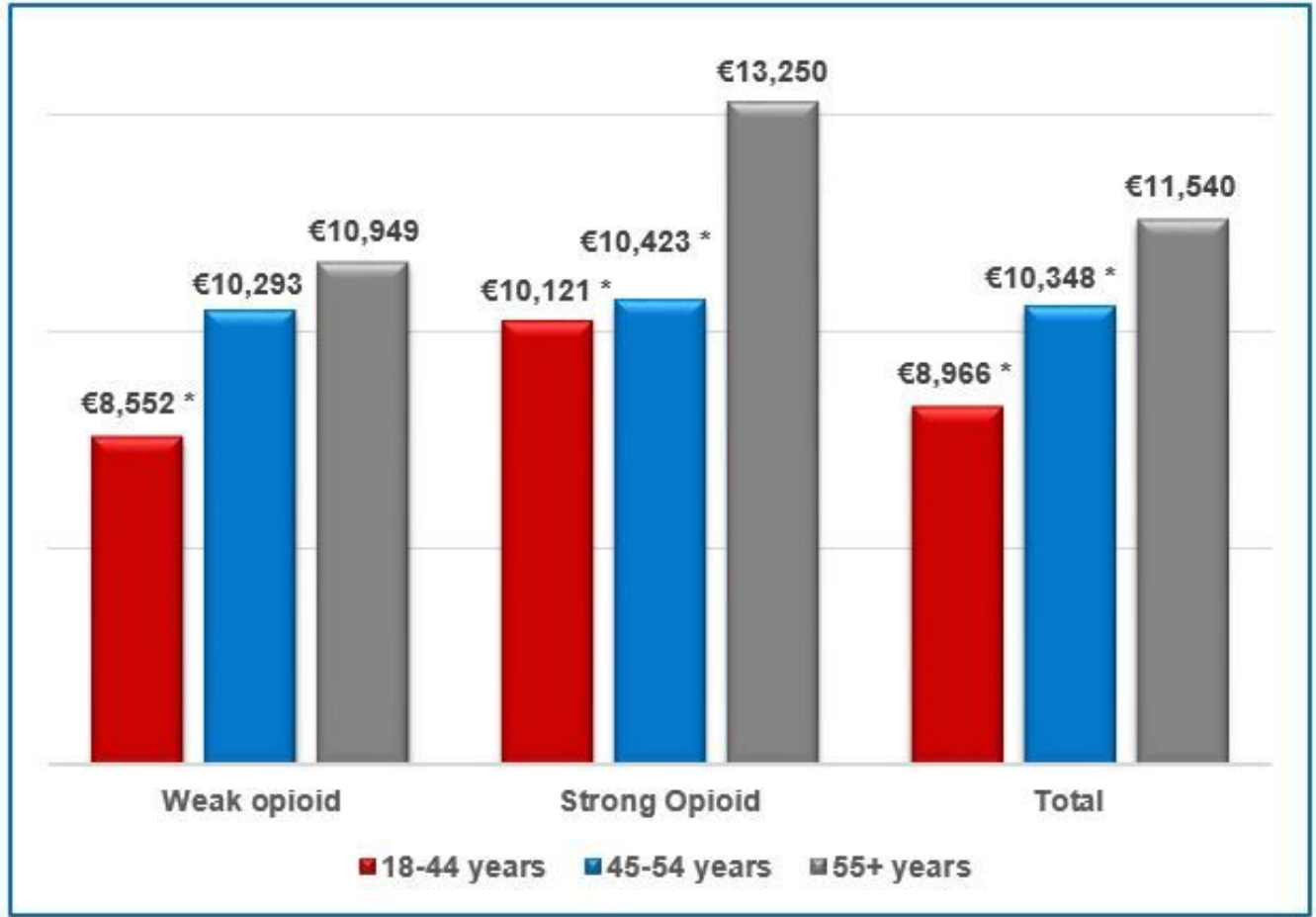

Figure 2

Mean cost per patient $(€)$ of sick leaves adjusted by covariates during follow up (36 months) by sex and age group. Values expressed as means. ${ }^{*} p<0.05$ (reference cohort: females and $55+$ years, respectively). Not significant when not indicated.

\section{Supplementary Files}


This is a list of supplementary files associated with this preprint. Click to download.

- SUPPLEMENTARYMATERIAL.docx 